\title{
Opportunities and challenges of compliance to safe building codes: Bangladesh and Nepal
}

Iftekhar Ahmed a*, Thayaparan Gajendran a , Graham Brewer a, Kim Maund a, Jason von Meding a ${ }^{* *}$, Humayun Kabir ${ }^{b}$, Mohammad Faruk ${ }^{c}$, Hari Darshan

Shrestha ${ }^{\mathrm{d}}$, and Nagendra Sitoula ${ }^{\mathrm{d}}$

a School of Architecture and Built Environment, University of Newcastle, Australia

$b$ Department of Geography and Environment, University of Dhaka, Bangladesh

c Department of Architecture, BRAC University, Bangladesh

d Institute of Engineering, Tribhuvan University, Nepal

* Corresponding author. Email: ifte.ahmed@newcastle.edu.au

${ }^{*}$ Conjoint based at the Florida Institute for Built Environment Resilience, University of Florida, USA

\author{
KEYWORDS \\ Bangladesh, Building codes, Compliance, \\ Disaster resilience, Grey Building Handbook, \\ Nepal
}

\section{DOI}

https://doi.org/10.30852/sb.2019.834

\section{DATES}

Received: 8 July 2019

Published (online): 3 September 2019

Published (PDF): 10 December 2019

\section{HIGHLIGHTS}

» Shared understanding on evidence-based knowledge as a critical component in the commitment to local action.

» Institutional and community awareness of the importance of compliance with and barriers to enforcement of codes. comprehensive literature review to identify potential solutions and gaps in terms of disaster resilience; and semi-structured interviews, including focus group discussions with stakeholders around challenges and opportunities for facilitating voluntary compliance to safe building codes. The findings were analyzed to understand how building codes might be more widely adopted to enable disaster resilience. A key output of the research is a training handbook on safe construction relevant to the informal sector and produced in local languages of the two case study countries.

\section{INTRODUCTION}

\subsection{The case for exploring building codes compliance}

In low-income countries, such as those in South Asia, building code frameworks are generally inadequate, reflecting the situation in the case study countries discussed here-Bangladesh and Nepal-where the bulk of buildings are constructed informally without adherence to building codes. Rough estimates indicate that over $80 \%$ of housing in these countries are built using informal construction (United Nations Human Settlement Programme [UN-HABITAT], 2010; World Bank, 2007). Even in the small proportion of formal sector housing, adherence to building codes is generally 
FIGURE 1. Recent disasters such as the Rana Plaza Garment Factory collapse in Bangladesh (left) (courtesy of Daily Star) and the 2015 Earthquake in Nepal that devastated many buildings (right) have raised local interest in building codes.
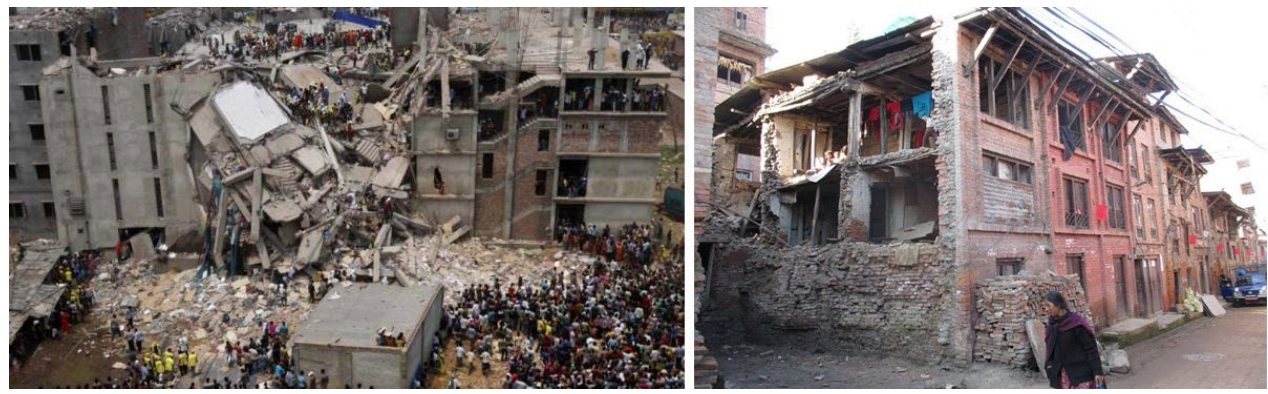

lacking or limited at best. Unlike developed countries, building codes are not integrated in building and planning regulations. Both Bangladesh and Nepal have building codes (Department of Urban Development and Building Construction [DUDBC], 2005; Housing and Building Research Institute [HBRI], 2015), but enforcement and compliance face significant challenges.

Affordability is a key constraint for the vast bulk of the population that builds informally. The codes provide good practice guidelines often based on developed country models and can thus be onerous and difficult to implement in the local socio-economic context. The codes also include guidelines for making buildings resilient to disasters, termed as "safe building codes". If these codes are followed to even a minimum, a level of disaster resilience can be achieved. To support this process, a "grey" document or guidance/training handbook, locally contextualized and achievable within the socio-economic constraints of developing countries, was developed as a key output of the project (Ahmed et al., 2018).

Both Bangladesh and Nepal face disaster risks from various types of hazards including earthquakes, floods, windstorms and landslides. Both countries are also severely threatened by climate change with increasing magnitude and frequency of hazards as indicated in the Global Climate Risk Index 2019 (Sarkar, 2018). These disasters exact a severe toll on buildings. Recent devastating disasters in Bangladesh and Nepal have spurred significant institutional and community interest and activity on disaster resilient construction and safe building codes (see Figure 1). Rising interest indicates there might be an opportunity for voluntary adoption of safe building codes and, therefore, providing a relevant and opportune time to undertake research on this issue.

The research problem presented is complex, multi-faceted and deeply entrenched in socio-economic, political and cultural conditions that have taken root over a long period of time. Addressing all of these complex issues would require a social transformation of a profound nature, and at this point in time, perhaps only the small beginnings of such transformation are evident from the increase in institutional interest in building codes after the 2015 earthquake in Nepal and the Rana Plaza building collapse in Bangladesh. The research conducted, therefore, does not intend to provide quick-fix or simple solutions, but rather identifies a plausible trajectory of social transformation that may realize a greater and more widespread voluntary compliance of safe building codes in the long term.

\subsection{Rationale for research context}

Within the Asia-Pacific region, South Asia has very low economic and human development; after Sub-Saharan Africa, it is the least developed region in the world (United Nations Development Programme [UNDP], 2015; World Bank, 2016). The region is also highly vulnerable to disasters (Gaiha, Hill, \& Thapa, 2012). A quarter of the world's population lives in South Asia (World Bank, 2016) and it is one of the most densely populated regions in the world. The impacts of disasters in the smaller South Asian countries are pronounced and recovery difficult because of their lower socio-economic status compared to the largest South Asian country, India (Sarma, 2015). The context of this research project is focused on two of the smaller South Asian countries, namely Bangladesh and Nepal, but can offer relevant lessons to the wider region. Transfer of lessons and cross-learning can be achieved between these countries due to the similarity in socio-economic conditions. Bangladesh and Nepal are disaster hotspots and recent events have instigated an interest in safe building codes, therefore allowing cross-learning between nations to achieve disaster resilience.

\section{METHODOLOGY}

The research methodology followed an exploratory approach, where ideas emerged from the data in an inductive vein. A set of research questions, linked with the aim and objectives, guided the research methodology, and comprised a combination of literature review and field investigations.

\subsection{Research questions}

In response to the research problem identified above, the following key exploratory research question 
was formulated: how can compliance to voluntary safe building codes be facilitated in the current contexts of Bangladesh and Nepal for increased disaster resilience?

To seek answers, the following set of sub-questions were posed:

»What are the strengths and weaknesses in terms of disaster resilience of building codes globally, and specifically in the project countries?

» What knowledge and insights can be gained from institutional and community stakeholders in the project countries on opportunities and challenges for facilitating compliance to safe building codes?

»What practice-and-policy guidelines are required to facilitate voluntary compliance and implementation of safe building codes?

\subsection{Aim and objectives}

The aim and objectives of the project are in line with the research question and sub-questions, and define the framework of activities:

Aim:

» To identify pathways for facilitating voluntary compliance to safe building codes for disaster resilience in Bangladesh and Nepal.

Objectives:

» Review global and local literature in the project countries including building codes and regulations to identify potential opportunities and gaps in terms of disaster resilience;

» Engage in consultations with key stakeholders at institutional and community levels to understand challenges and opportunities for facilitating voluntary compliance to safe building codes;

» Produce practice-and-policy guidelines for facilitating voluntary compliance and implementation of safe building codes extending to informal sector buildings;

» Involve early career researchers in the project countries to meet the project objectives and thereby build local research capacity; and

» Explore the possibilities of forming networks and cross-learning between the project countries and wider regional and international knowledge dissemination.

\subsection{Methodological approach}

To answer the research questions and sub-questions, a qualitative exploratory methodology was adopted as it assists in developing as complete an account of the phenomenon under investigation as possible (Quinlan, 2011). The intent of the research is well-aligned with this approach in that it explores subjective experiences of specialist practitioners to understand the phenomenon.

The methodology comprised two components. The first involved a comprehensive literature review. Both academic and grey literature were reviewed to identify potential solutions and gaps in terms of disaster resilience. The second involved semi-structured interviews and focus group discussions to identify challenges and opportunities for facilitating voluntary compliance with safe building codes.

\section{RESULTS AND DISCUSSION}

\subsection{Overview of the global literature review}

The results of the literature review show that the outcome of many disaster events can be traced to societal decisions in relation to land-use planning (development location) and building systems (construction techniques). Conversely, building and planning regulations are considered a powerful tool for increasing community resilience and reducing risk to disaster events (Bernicat, 2015; World Bank, 2015). Along with the UN, prominent international development agencies such as the World Bank, United States Agency for International Development (USAID) and Japan International Cooperation Agency (JICA) are attempting to address the global priority of resilient buildings and are promoting the uptake, compliance and implementation of safe building codes (JICA, 2016; USAID, 2016; World Bank, 2015). As the World Bank's Global Facility for Disaster Risk Reduction (GFDRR) (2016) aptly states: "Building code compliance saves lives" (p. 2), an indication of its intent to promote building code compliance. Although building codes and regulations are often used simultaneously, they are significantly different in meaning and scope. The broader term "building regulations" used in developed countries often refers to both land-use planning and building codes (World Bank, 2015). However, in many developed countries such as Australia, there is a division between building codes and regulations, where building codes relate to technical building provisions or construction requirements (Australian Building Codes Board [ABCB], 2018) and regulations concentrating on administrative processes such as building and planning permits (e.g. New South Wales Environmental Planning and Assessment Act, 1979). What is important, though, is that the integration of building codes and regulations has been advantageous in minimizing the impact of disasters. Their importance as a mechanism to protect life and build community resilience has become the focus of countries more recently (United Nations Economic and Social Commission for Asia and the Pacific [UNESCAP], 2012). Japan, for example, maintains some of the world's 
strictest codes, although it has taken more than seven decades and a series of disasters for the country to have reached this level (Glanz, \& Onishi, 2011).

The situation is vastly different for many developing countries where building codes are often not mandatory (Thiruppugazh, 2008). Bangladesh has a National Building Code, yet it has been explained that "the Building Code is not an independent legislation or act, rather it is a national level approved document" (HBRI \& Bangladesh Standard Testing Institute [BSTI], 2006, p. iv). In addition, in developing countries, it is widely reported that enforcement and compliance of codes face serious barriers, including ineffective governance and corruption (GFDRR, 2014), adding further complexity and resulting in greater vulnerability to disasters.

Building codes may be prescriptive- or performance-based. While prescriptive regulations are generally inflexible, performance-based codes provide more flexible approaches. This flexibility allows for the development of alternative solutions to suit individual building requirements, i.e., achieving the same regulatory goal, but from a different perspective (Cote \& Grant, 1988; Gann, Wang, \& Hawkins, 1998). This approach was considered relevant in this project because of the limitations of the regulatory framework in the case study countries.

The brief literature review highlighted systemic irregularities, lack of legitimacy and procedural justice as key issues impeding compliance in developing countries, and not necessarily the absence of codes. Furthermore, attention is drawn to the need for more contextualized codes that address issues associated with the more traditional means of construction in rural areas and urban informal settlements. Safety in the built environment is a priority for governments and the essential purpose of building codes and regulations. However, codes are of no use if there is a low level of compliance, hence the examination of the various subjects that relate to building codes and compliance with a brief comparison of practices in developed countries and developing countries was undertaken in this project.

\subsection{Findings from the case studies}

Empirical investigations were conducted in parallel in the two case study countries, Bangladesh and Nepal, as well as reviews of local literature and building codes. A wide range of stakeholders were consulted from academia and industry, as well as at the low-income community level through masons. The key findings from the case study investigations are summarized below.

\subsubsection{Bangladesh}

Bangladesh, a small country, hosts a large population where the capital city, Dhaka, accommodates close to 20 million people. The investigations focused largely on Dhaka because of its national prominence. Due to the large population, the city has been growing in a very irregular form and has urbanized in a very haphazard manner. Building construction at present, and in the past, is not given due attention particularly with regard to the existing building regulations and codes (see Figure 2). Therefore, over $90 \%$ of buildings that have already been constructed in the city are highly vulnerable to earthquakes and other hazards. The city has experienced several large building collapses where many people have died, many of which were not due to natural hazard events, but rather because of deficient construction that did not follow building codes. Given this situation, it is extremely important for the city, and the whole country, to identify effective mechanisms to promote the implementation of building codes. Those who deal with the Bangladesh National Building Code (BNBC) (e.g. engineers) should be trained at the university level through incorporating it into the curriculum; at the moment, the codes are not dealt with in sufficient detail in the curriculum. In addition, workers in the building construction industry can be trained through various ways such as providing incentives or rewards, and implementation of the BNBC can be promoted through such training.

In Bangladesh, cities like Dhaka experience widespread violation of building codes. A large number of buildings that have already been constructed in Dhaka in a haphazard manner are at risk of collapse during earthquakes and other hazards; according to a survey of a national daily newspaper, about 78,000 buildings out of 326,000 in Dhaka have been identified as vulnerable to disasters (Sarker, 2009). Therefore, there remains a need for the city to identify mechanisms on how to effectively comply with building codes. In this case, continuous assessment of opportunities and challenges can assist in direct action. Future research can include assessing

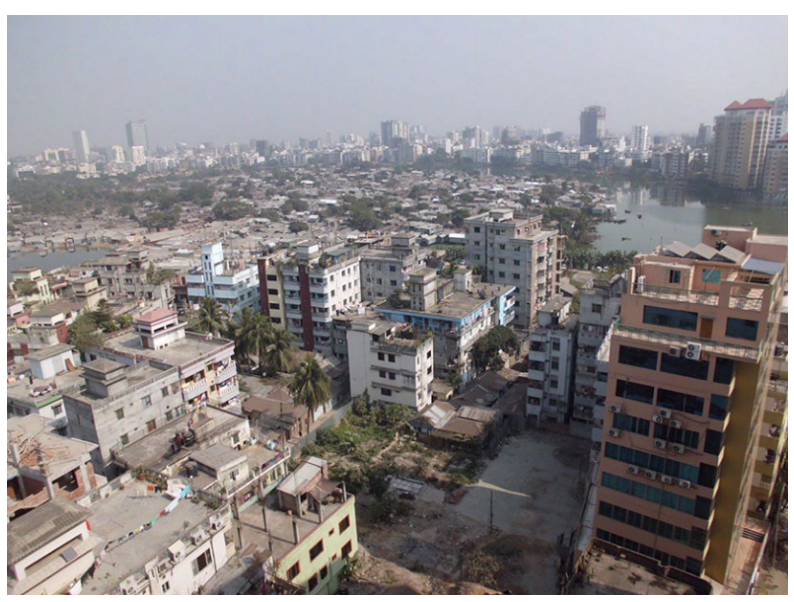

FIGURE 2. In rapidly urbanizing Dhaka, little attention is given to building codes. 
different stakeholders' opinions at a larger scale that also encompasses all city communities so that they can freely share their ideas and experiences. In addition, taking examples from countries where building codes are successfully implemented and research activities to explore mechanisms to promote such application of codes can be initiated.

\subsubsection{Nepal}

The investigations in Nepal were undertaken in three municipalities and focused on earthquakes because most of the building codes relate to this hazard after the massive earthquake in 2015. It was found that there are significant activities by the municipal authorities including public awareness campaigns, different levels of training such as mason training, dissemination of the National Building Code (NBC) by megaphones and media channels, and weekly household owner counselling for building permit applications. At the state level, guidelines, construction specifications, pamphlets and prototype designs have been developed, together with training on safe building construction for engineers, sub-engineers, assistant sub-engineers and masons. However, the NBC has focused more on new or modern technology, such as reinforced concrete. The highly dense traditional settlements have specific construction characteristics which the NBC has not been able to take into consideration in its work.

One of the biggest challenges is the lack of awareness of homeowners regarding safety, the NBC and its compliance (see Figure 3). In the older parts of cities such as in Kathmandu, buildings had been constructed a long time ago following traditional styles when building codes did not exist in Nepal and often stand on small lots, and implementation of the NBC in these areas is difficult. Large stocks of old buildings exist, which were not built according to building codes and where retrofitting is challenging; provision of transport accessibility in these

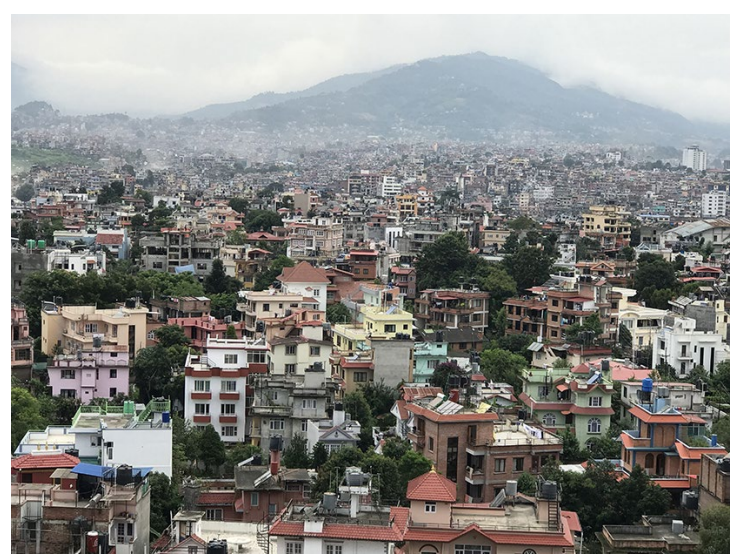

FIGURE 3. In rapidly urbanizing cities of Nepal, such as in the Kathmandu valley, buildings are constructed with no awareness of building codes. densely built areas with small lot sizes as required by current codes would be impossible without demolition of buildings. Construction is often not undertaken under the supervision of skilled built environment professionals (engineers and architects) due to economic constraints. Many such professionals lack sufficient design knowledge, especially in city centres where structures such as high-rise buildings are being constructed. At the government level, there is inadequate institutional capacity and political interference. Thus, the study recommends capacity development, raising awareness of different stakeholders, solutions for retrofitting existing buildings, and incentive mechanisms. Further studies are needed to find ways to formalize and standardize safe construction using traditional technology (i.e. for informal settlements).

\subsection{Discussion of key results}

The discussion of the key results of the research is structured along the main research question and sub-questions, drawn from the literature review and case studies, and summarized below.

3.3.1 Response to sub-question 1: Strengths and weaknesses of building codes

» Building regulations vs building codes: A key weakness in developing countries, including the case study countries, is the lack of distinction between building regulations and building codes. Building codes and regulations are often used simultaneously, but their scope and meaning vary.

» Integration of building regulations and building codes: The level of differentiation and integration between regulations and codes varies widely, both in developed and developing countries, making compliance and enforcement complex for achieving disaster resilience.

» Mounting emphasis to act: In many developing countries, building codes exist but implementation is often not mandatory. However, after recent disasters in the case study countries, there is a stronger emphasis on the implementation of codes.

» Need for greater intervention: Despite the mounting emphasis on many existing challenges in terms of capacity, compliance and enforcement, there is little knowledge of them even among built environment professionals.

3.3.2 Response to sub-question 2: Knowledge and insights from stakeholders

\section{Challenges:}

» Large informal sector: As mentioned in the 

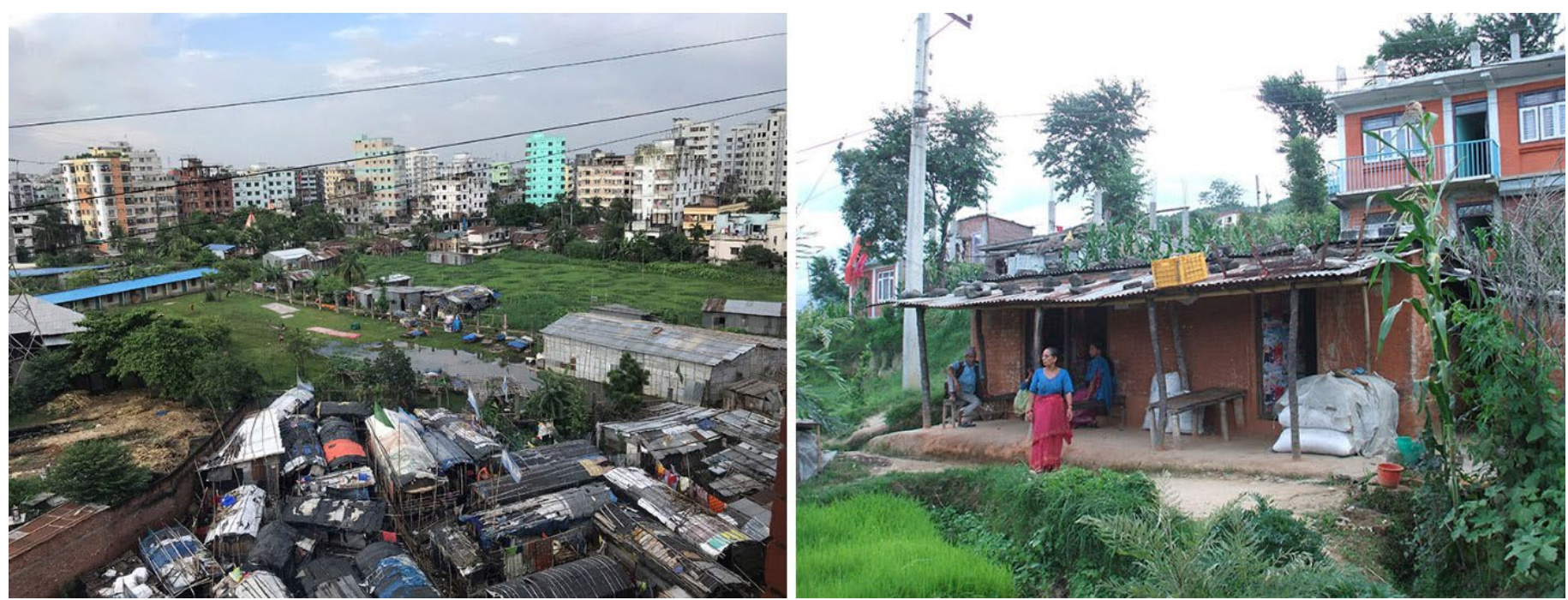

FIGURE 4. In both Bangladesh (left) and Nepal (right) there is a variety of informal construction from brick-and-concrete buildings to buildings made of traditional and less durable materials.

Introduction, section 1.1., a vast bulk of buildings in both these countries are built informally. In Nepal, there is an attempt to contextualize building codes for small buildings and those built with traditional materials using a "Mandatory Rule of Thumb" approach, but there is no such effort in Bangladesh (see Figure 4).

" Lack of awareness and knowledge: Although building codes exist in both countries, there is a widespread lack of awareness and knowledge on how to understand and apply the codes. Codes are often understood as increasing resilience only to earthquakes, and not the wider range of hazards that impact these countries.

» Lack of capacity: There is a need for capacity building at all stakeholder levels from formally trained built environment professionals to informal sector construction workers.

" Perception of extra cost: Building codes are widely perceived as costly and hence avoided, without any serious cost-benefit analysis presented by professionals or demanded by building owners.

» Corruption: Building codes are by and large ignored, if known at all, and building approvals are often received through bribery. Often such corrupt acts are facilitated through political connections; political patronage and bribery are some of the key corruption instruments.

Opportunities:

» Institutional initiatives: In Bangladesh, there is a building resilience program supported by the World Bank. Similarly, in Nepal, there is strong international support and the government has mandated the implementation of building codes, which provides an opportunity for promoting compliance.

"Educational initiatives: There are some initiatives to include education on building codes at the tertiary level such as at the Bangladesh University of Engineering and Technology (BUET) and the Institute of Engineering, Tribhuvan University, Nepal.

» Awareness and capacity building: There are quite a few initiatives in Nepal such as the "Earthquake Safety Day" and training of masons. While Bangladesh is lagging behind, there is an opportunity for the country to learn from these initiatives.

3.3.3 Response to sub-question 3: Practice-and-policy guidelines for voluntary compliance

»Increasing awareness: There is scope for a much more concerted and extensive effort to raise awareness. Policies could be implemented through public, private and civil society partnerships.

»Professional bodies reinforcing codes in education: Policies should be targeted for capacity building at the tertiary level education of built environment professionals to the training of construction workers. The "Grey Building Handbook" produced in this project can serve as a training manual for informal sector builders (Ahmed et al., 2018).

» Financial incentives for compliance: A range of policy instruments including financial incentives, "reward-and-punishment", and regulatory code of professional practice could move forward the agenda for building code compliance.

» Formation of new authorities/institutions: There is the need for a specific authority for implementation and enforcement of building codes.

» More integrated and targeted guides: There is scope here for the integration of codes and 
regulations, as well as building codes dealing with a wider range of hazards.

\subsubsection{Responses to the main research question}

Various approaches were suggested in the interviews and literature to catalyze voluntary compliance such as incentives, tax benefits, reduced insurance premiums and reverse mortgages, inclusion in educational curricula and school buildings, contextualized approaches according to country, sector-wide training that includes construction workers and informal builders, and perhaps most importantly, raising awareness. A mixture of such strategies in varying extents in the formal and informal sectors as discussed below can be an effective way forward in addressing the main research question.

\section{Formal sector}

In Bangladesh and Nepal, there are already initiatives for implementing building codes and regulations in the formal sector although gaps exist in the coverage and reports of violation and corruption. Capacity building, financial incentives, education and enforcement (fines, rewards, monitoring of practitioner licensing, etc.) are suggested mechanisms for promoting voluntary compliance. There is some evidence of low-scale voluntary implementation and these can be a basis for upscaling voluntary compliance initiatives.

\section{Informal sector}

Raising awareness is the main pathway to achieving voluntary compliance in the informal sector. A large part of the population in the case study countries live in informal settlements and rural areas, and the high-rise building standards specified in the codes are simply not feasible. Therefore, it makes sense to begin with the most basic and critical life-saving codes, embodied in the Grey Building Handbook, which is a training manual derived from the research contextualized for Bangladesh and Nepal, where a suite of safe building options is presented to match different incomes and site conditions (Ahmed et al., 2018). The approaches in Nepal, such as specific codes for traditional and small buildings and training of masons, address the safety needs of the large informal sector. While there is scope for upscaling these approaches in Nepal, there is also an opportunity for Bangladesh to benefit from these practices, and contextualize and implement such approaches.

\section{CONCLUSION}

The overarching goal of this project was to undertake research on approaches and options for promoting voluntary compliance to safe building codes for disaster resilience, focusing on two case study contexts Bangladesh and Nepal. A secondary, though equally important, goal was to develop a handbook that would enable practitioners, local builders and construction workers in low-income communities to begin the process of constructing disaster-resilient buildings and eventual compliance to building codes.

The project has revealed valuable lessons from the resonance of the findings of the literature review and empirical investigations. The similarity of findings in the two case study countries indicate the problem being related to issues of governance, institutional and technical capacity, and public awareness. Despite the similarities, there were lessons unique to each country, providing an opportunity for sharing of lessons through collaborative research and the considerable benefits that can arise from knowledge sharing and the cross-fertilization of expertise and ideas. Experience from the project has shown that the engagement of a wide range of stakeholders in both countries has helped raise awareness of the building codes issue. Compliance to building codes is a complex issue, yet the signs uncovered of growing awareness and initiatives indicate that disaster resilience through widespread voluntary compliance of safe building codes and regulations is a possibility that might be realized over time in the future.

The research is significant because disaster resilience is of high national concern in both Bangladesh and Nepal because of the frequent and various disasters that impact these countries. At the global level, the significance of the project lies in its alignment to the UN's global agendas including the Sendai Framework for Disaster Risk Reduction and the Sustainable Development Goals, both of which promote safe building practices.

\section{ACKNOWLEDGEMENTS}

Acknowledgements are due to the Asia-Pacific Network for Global Change Research (APN) for a Collaborative Regional Research Programme (CRRP) grant and the School of Architecture and Built Environment, University of Newcastle, Australia, for back-up funding to undertake the research on which this paper is based. Acknowledgements are also extended to the project's research assistants Josephine Vaughan, Georgia Kissa, Oluwadunsin Ajulo, Shaiful Islam Bhuiyan and Inu Pradhan-Salike.

\section{REFERENCES}

Ahmed, I., Gajendran, T., Brewer, G., Maund, K., von Meding, J., Kissa, G., ... \& Sitaula, N. (2018). Grey building handbook. Callaghan, NSW: University of Newcastle. Retrieved from https://cifal.newcastle. edu.au/wp-content/uploads/2019/10/APN-greybuilding-handbook.pdf

Australian Building Codes Board. (2018). National 
construction code. Retrieved on 28 June 2019 from https://www.abcb.gov.au/ncc-online/About

Bernicat, M. (2015). Rana Plaza two-year anniversary. The Daily Star (25 April 2015). Retrieved on 28 June 2019 from https://www.thedailystar.net/op-ed/ rana-plaza-two-year-anniversary-79109

Cote, A., \& Grant, C. (1988). Codes and standards for the built environment. In J. Sime, Safety in the Built Environment. Michigan: E. \& F. N. Spon.

Department of Urban Development and Building Construction. (2005). Nepal national building codes. Kathmandu: Department of Urban Development and Building Construction (DUDBC).

Gaiha, R., Hill, K., \& Thapa, G. (2012). Natural Disasters in South Asia. In Routledge Handbook of South Asian Economics (pp. 129-148). Routledge.

Gann, D., Wang, Y., \& Hawkins, R. (1998). Do regulations encourage innovation? - The Case of energy efficiency in housing. Building Research \& Innovation, 26(5), 280-296.

Global Facility for Disaster Reduction and Recovery. (2016). Building Regulation for Resilience: Managing Risks for Safer Cities. Retrieved on 28 June 2019, from https://www.gfdrr.org/sites/default/files/ publication/Building_Regulation_for_Resilience_ Managing_Risks_for_Safer_Cities.pdf

Global Facility for Disaster Reduction and Recovery. (2014). Improving building code implementation and compliance for more resilient buildings in developing countries: considerations for policy makers. Washington: World Bank Group.

Glanz, J., \& Onishi, N. (2011). Japan's strict building codes saved lives. New York Times (11 March 2011). Retrieved on 28 June 2018 from http://www.nytimes. com/2011/03/12/world/asia/12codes.html

House Building Research Institute, \& Bangladesh Standard Testing Institute. (2006). Bangladesh national building code. Dhaka: House Building Research Institute (HBRI) and Bangladesh Standard Testing Institute (BSTI).

Housing and Building Research Institute. (2015). Bangladesh national building code. Dhaka: Housing and Building Research Institute (HBRI).

Japan International Cooperation Agency. (2016). Disaster prevention of buildings (against earthquake, tsunami, typhoon, fire, etc.). Tokyo: Japan International Cooperation Agency (JICA).

Quinlan, C. (2011). Business research methods. United Kingdom: Thomas Rennie.

Sarkar, S. (2018). South and Southeast Asia most at risk by climate change. Retrieved on 14 November 2019 from https://www.thethirdpole.net/en/2018/12/05/ south-and-southeast-asia-most-at-risk-by-climate-change/

Sarker, P. K. (2009). 2.5 lakh buildings in three cities at earthquake risk. BD News (28 August 2009). Retrieved 17 October 2018 from https://bdnews24.com/bangladesh/2009/08/28/2.5-lakh-buildings-in-threecities-at-earthquake-risk

Sarma, C. (2015). Enhancing disaster management capacity in South Asia. Singapore: Institute of South Asian Studies.

Thiruppugazh, V. (2008). Urban vulnerability reduction: regulations and beyond. In R. Jha (Ed.), The Indian Economy Sixty Years after Independence. London: Palgrave Macmillan.

United Nations Development Programme. (2015). Human development report 2015. New York: United Nations Development Programme (UNDP).

United Nations Economic and Social Commission for Asia and the Pacific. (2012). Integrating environmental sustainability and disaster resilience in building codes. Bangkok: United Nations Economic and Social Commission for Asia and the Pacific (UNESCAP) and Asian Institute of Technology.

United Nations Human Settlement Programme. (2010). Nepal: urban housing sector profile. Nairobi: United Nations Human Settlement Programme (UN-HABITAT).

United States Agency for International Development. (2016). Building code implementation program in municipalities of Nepal. Kathmandu: United States Agency for International Development (USAID).

World Bank. (2007). Dhaka: improving living conditions for the urban poor. Dhaka: World Bank Office.

World Bank. (2015). Building regulation for resilience managing risks for safer cities. Washington DC: World Bank.

World Bank. (2016). South Asia. Retrieved on 28 June 2019 from http://data.worldbank.org/region/south-asia

\section{CORRECTION NOTICE}

In the article "Ahmed, I., Gajendran, T., Brewer, G., Maund, K., von Meding, J., Kabir, H., ... Sitoula, N. (2019). Opportunities and challenges of compliance to safe building codes: Bangladesh and Nepal. APN Science Bulletin, 9(1). doi:10.30852/sb.2019.834", a correction was made on 1 June 2021 at the corresponding author's request to include the following entry in the references list of the paper: Ahmed, I., Gajendran, T., Brewer, G., Maund, K., von Meding, J., Kissa, G., ... \& Sitaula, N. (2018). Grey building handbook. Callaghan, NSW: University of Newcastle. Corresponding to the correction, citations have been included within the text in sections 1.1, 3.3.3 and 3.3.4, accordingly. 